\section{The Mental Health Act Commission and detained patients}

\section{DEAR SIRS}

The leaflet designed by Dr Philip Sugarman and Ms Angela Long (Psychiatric Bulletin, 1992, 16, 549) for the needs of informal patients is to be warmly welcomed.

Unfortunately it contains a fundamental error in relation to their description of the role of the Mental Health Act Commission. The Commission is a Special Health Authority and its primary statutory function is to keep under review the operation of the Mental Health Act in respect of patients detained under the Act. Its statutory remit is therefore essentially confined to detained patients.

As far as patients' complaints are concerned the Commission's jurisdiction is complex but can be summarised as follows.

(a) The Commission can investigate any complaint made by a person in respect of a matter that occurred while he or she was detained under the Act and which the complainant considers "has not been satisfactorily dealt with by the Managers of that Hospital or Mental Nursing Home"; and

(b) the Commission can investigate any other complaint "as to the exercise of the powers of the discharge of the duties conferred or imposed by [the] Act in respect of a person who is or has been detained".

If informal patients have a complaint about something that occurred while they were detained in hospital under the Act then the Mental Health Commission has the power to deal with this. What the Commission cannot do is deal with any complaint they may have which arises during the time that they were informal patients in hospital.

WiLliam BingleY

Chief Executive

Mental Health Act Commission
Maid Marian House
56 Hounds Gate
Nottingham
NG1 $6 B G$

\section{Lessons from community care of mentally handicapped ex-patients}

DeAR SIRS

It is ten years since the policy of care in the community for long-stay hospital mentally handicapped in-patients was introduced. Ex-patients have now been living in the community long enough for problems to begin coming home to roost. In Leeds, from 1982 to 1992,190 mentally handicapped people moved from hospital into group homes, private residential accommodation and establishments run by housing association and voluntary or charitable agencies. A range of issues can be recognised many emerge gradually after an initial honeymoon period.

Incompatibility. Staff and residents in the confined space of community houses face more intensive and intimate personal relationships than in large hospital wards. Tensions can arise among residents and between staff and residents. Before discharge residents may have been matched for compatibility and lived together, but this is no guarantee that harmony will be sustained. Some residents have an itch to move, feeling that the grass on the other side is greener.

Accidents and Injuries to ex-patients inevitably occur. After serious fractures, mentally handicapped people may need prolonged physiotherapy and rehabilitation to restore their mobility when it may not be practical for them to live in their community setting. Some return to a mental handicap hospital for a time to receive this treatment.

Recurrence of mental illness. Some community facilities are staffed by people who have no specialist training in mental illness who can have difficulty coping with psychiatric symptoms. Untrained staff may be fearful of such residents. Some care workers have idiosyncratic views on how such patients should be treated, so that teaching, counselling and ready support of care staff are essential. Furthermore, staff may not be able to administer medication with the flexibility and urgency applicable in hospital.

Resurgence of challenging behaviour in a community residence can have a knock-on effect. It disturbs other residents and staff and can become intolerable.

Increasing dependency with ageing and physical and mental deterioration can occur; dementia is increasingly diagnosed in mentally handicapped people. Staff may not be able to treat residents with developing dependency who may need care in a nursing home or mental handicap hospital.

Community supervision. When people have been diffused into the community overall supervision of change is not possible. Subtle changes may not be recognised by untrained staff with a frequent turn-over. Problems patients had in hospital do not disappear in the community, despite the less regimented, more private and domestic environments, but regular visiting by experienced professionals who know the patients can lessen the risk of breakdown. 